Original Article

\title{
Electromyography of symmetrical trunk movements and trunk position sense in chronic stroke patients
}

\author{
Chien-Fen Liao'), Lih-Jiun Liaw ${ }^{2,3)}$, Ray-Yau WanG ${ }^{4)}$, Fong-Chin Su ${ }^{5,6)}$, Ar-Tyan Hsu ${ }^{1,7)^{*}}$ \\ 1) Institute of Allied Health Sciences, College of Medicine, National Cheng Kung University: No 1, \\ Ta-Hsueh Road, Tainan 701, Taiwan \\ 2) Department of Physical Therapy, College of Health Science, Kaohsiung Medical University, Taiwan \\ 3) Department of Rehabilitation Medicine, Kaohsiung Medical University Hospital, Taiwan \\ 4) Department of Physical Therapy and Assistive Technology, National Yang-Ming University, Taiwan \\ 5) Department of Biomedical Engineering, National Cheng Kung University, Taiwan \\ 6) Medical Device Innovation Center, National Cheng Kung University, Taiwan \\ 7) Department of Physical Therapy, College of Medicine, National Cheng Kung University, Taiwan
}

\begin{abstract}
Purpose] To explore the differences in bilateral trunk muscle activation between chronic stroke patients and healthy controls, this study investigated the symmetry index and cross-correlation of trunk muscles during trunk flexion and extension movements. This study also assessed the differences in trunk reposition error between groups and the association between trunk reposition error and bilateral trunk muscle activation. [Subjects and Methods] Fifteen stroke patients and 15 age- and gender-matched healthy subjects participated. Bilateral trunk muscle activations were collected by electromyography during trunk flexion and extension. Trunk reposition errors in trunk flexion and extension directions were recorded by a Qualisys motion capture system. [Results] Compared with the healthy controls, the stroke patients presented lower symmetrical muscle activation of the bilateral internal oblique and lower cross-correlation of abdominal muscles during trunk flexion, and lower symmetry index and cross-correlation of erector spinae in trunk extension. They also showed a larger trunk extension reposition error. A smaller trunk reposition error was associated with higher cross-correlation of bilateral trunk muscles during trunk movements in all subjects. [Conclusion] Trunk muscle function during symmetrical trunk movements and trunk reposition sense were impaired in the chronic stroke patients, and trunk position sense was associated with trunk muscle functions. Future studies should pay attention to symmetrical trunk movements as well as trunk extension position sense for patients with chronic stroke.

Key words: Stroke, Electromyography, Trunk reposition sense
\end{abstract}

(This article was submitted Apr. 2, 2015, and was accepted May 23, 2015)

\section{INTRODUCTION}

The function of trunk muscles in patients with stroke is compromised, and this is reflected in many aspects, such as decreased muscle strength ${ }^{1-3)}$, poor postural control ${ }^{4,5)}$, and impaired functional activities ${ }^{6-8)}$. Although a greater extent of bilateral hemispheric input innervates the axial trunk muscles than lateral limb muscles ${ }^{9-11)}$, upper motor neuron lesions still cause detectable functional changes in trunk control $^{2)}$.

Previous studies have investigated electromyographic (EMG) activities of trunk muscles, including the rectus abdominis (RA), and external abdominal oblique (EO), and large back muscles, the latissimus dorsi (LD) and lumbar

*Corresponding author. Ar-Tyan Hsu (E-mail: arthsu@mail. ncku.edu.tw)

(C2015 The Society of Physical Therapy Science. Published by IPEC Inc. This is an open-access article distributed under the terms of the Creative Commons Attribution Non-Commercial No Derivatives (by-ncnd) License $<$ http://creativecommons.org/licenses/by-nc-nd/3.0/>. erector spinae (ES), during trunk flexion and extension movements to clarify the deficits of neuromuscular control in stroke patients ${ }^{12-14}$ ). Voluntary trunk flexion or extension is a symmetrical movement and could be used to reflect differences in neuromuscular control between sides. A previous study reported that the activities of the RA and LD on the paretic side were decreased in patients with stroke compared with healthy control subjects based on the symmetry index (SI), which reflects the difference between the activation magnitudes of corresponding trunk muscles ${ }^{12)}$. The SI values acquired during the performance of upper and lower limb flexion tasks were associated with deficiencies in clinical measurements, that is, the Motor Assessment Scale and Barthel Index ${ }^{5}$. In addition, lower temporal synchronization (represented by the value of cross-correlation) of the RA, $\mathrm{EO}, \mathrm{LD}$, and ES of the affected side versus the unaffected side was found in patients than in control subjects. Crosscorrelation was used to represent the temporal synchronization between sides (paretic versus non-paretic and right versus left) or between axial and lateral ipsilateral trunk muscles ${ }^{12)}$, and a higher value meant better temporal synchronization. Cross-correlation shows that the patients who 
had experienced a stroke less than 3 months previously had decreased trunk muscle function, but it is unclear whether there was any deficit in paretic versus non-paretic trunk muscle activation during symmetrical trunk movements in chronic patients.

During most voluntary trunk movements, trunk muscles are frequently activated at submaximal levels ${ }^{15}$. For the execution of most activities of daily living, proper proprioceptive inputs are essential to signal the CNS to activate trunk muscles, to generate an adequate submaximal force, and to monitor the progression of trunk movement ${ }^{16)}$. Trunk proprioception could be reflected by the trunk reposition error (TRE), which shows the difference between a target trunk position and the position a subject chooses while attempting to reproduce the target position ${ }^{16)}$. TRE has been reported to be increased in older adults with impaired balance ${ }^{17}$, peripheral neuropathy ${ }^{18)}$, and low back pain ${ }^{19}$ ). Previous studies have investigated the joint position sense of the upper and lower limbs in patients with stroke ${ }^{20-23)}$. However, only one study has been conducted to investigate trunk position sense in a stroke population. Ryerson et al. showed that TRE were correlated with several clinical measurements, such as the Berg Balance Scale, and Postural Assessment Scale for Stroke ${ }^{16)}$. It is unclear whether a relationship exists between trunk muscle function during trunk voluntary movements and trunk proprioception in not only stroke patients but also healthy subjects.

The purposes of this study were to investigate the symmetry index and temporal synchronization of corresponding bilateral trunk muscles between patients with chronic stroke and age-matched healthy controls during symmetrical trunk flexion and extension movements and to explore whether there is a deficit in trunk position sense in stroke patients. This study also assessed the association of the trunk position error with the symmetry index and temporal synchronization of bilateral trunk muscle activation for both groups and for all subjects.

\section{SUBJECTS AND METHODS}

The stroke group included 15 patients $(7$ males and 8 females; averaged ages, $50.3 \pm 7.7$ years; average height, $162.7 \pm 7.8 \mathrm{~cm}$; average weight, $71.3 \pm 12.9 \mathrm{~kg}$ ) and 15 healthy age-match control subjects (average age, $50.4 \pm$ 8.1 years; average height, $164.9 \pm 7.1 \mathrm{~cm}$; average weight, $65.8 \pm 10.4 \mathrm{~kg}$ ). The inclusion criteria for the patients were as follows: 1) first time stroke patients with unilateral hemiplegia or hemiparesis, 2) medically stable for over 6 months, 3) able to sit independently, 4) able to follow three-step commands, and 5) no other neuromuscular diseases or vestibular dysfunctions. All patients were first time stroke patients who experienced stroke an average of $4.6 \pm 4.7$ years previously. Of the 15 patients, 10 had right hemispheric pathologies, and 9 sustained cerebral infarction. The study protocol was approved by the Institutional Review Board of Kaohsiung Medical University Chung-Ho Memorial Hospital (IRB No. KMUH-IRB-990274). Each subject signed an informed consent form before testing. The mean Mini-Mental Status Examination score was high for all patients $(28.1 \pm 2.4)$, indicating that all patients were capable of following instruc-

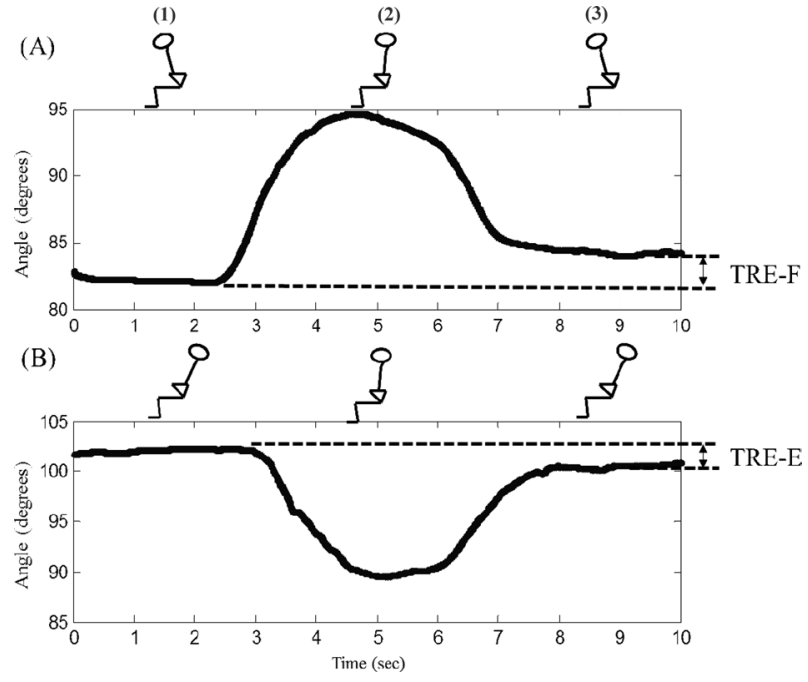

Fig. 1. Trunk angles and illustrations of the positions during the trunk position sense tests

(A) TRE in flexion direction. (B) TRE in extension direction. (1) This was the target position. (2) The subject was asked to return to the upright position. (3) The subject was asked to reproduce the same target trunk position actively. TRE was be the difference between the target angle and the reposition angle.

tions to perform the tasks asked of them. Trunk control was assessed in the patients with the Trunk Impairment Scale ${ }^{24)}$, and the mean score was $16.6 \pm 4.2$, indicating a moderate to very good trunk control ability and the ability to sit independently. In addition, patients had a high level of function in daily living (Barthel Index $98.7 \pm 2.3)^{25)}$.

During the trunk movement tasks, the subjects sat on a chair with a back that allowed them to recline backward at a thigh to trunk angle of $130^{\circ}$. The subjects folded their arms and moved at a self-selected speed when instructed verbally to perform trunk flexion (TF) to move into the upright position. For the trunk extension condition (TE), the subjects leaned their trunks forward until their folded arms touched their thighs. Following a verbal cue, the subjects returned to the upright position by extending their trunks without pushing their arms against their thighs.

TRE was assessed with the subjects blindfolded and sitting with their arms folded against their chests. After practicing, the subjects were moved to a target trunk position passively, this position was held for approximately 3 seconds, and then they were returned to the upright position; they were then asked to reproduce exactly the same target trunk position actively at a comfortable pace (Fig. 1). Three trials each were performed in the flexion (TRE-F) and extension (TRE-E) directions. The subjects were required to maintain an upright posture while sitting. Upright posture was defined as one in which the subjects maintained the trunk in line with the gravity. Thus, the position sense concerned in the present study was the angle of the trunk relative to the thighs (which were, in turn, supported by the seat of the chair). Therefore, the trunk angle rather than intervertebral motions was considered to reflect trunk control in the sitting posture ${ }^{16)}$.

The surface EMG electrodes were placed on the bellies of 
Table 1. Comparison of EMG variables between groups during trunk movement tasks

\begin{tabular}{|c|c|c|}
\hline $\mathrm{TF}$ & Stroke & Control \\
\hline RA-SI ${ }^{b}$ & $-0.118-0.195(-0.026)$ & $-0.069-0.026(0.013)$ \\
\hline IO-SI ${ }^{\mathrm{a},{ }^{*}}$ & $-0.229(-0.243)$ & $-0.007(-0.251)$ \\
\hline $\mathrm{EO}-\mathrm{SI}{ }^{\mathrm{a}}$ & $-0.099(-0.380)$ & $-0.044(-0.300)$ \\
\hline $\mathrm{RA}-\mathrm{CC}^{\mathrm{b},{ }^{*}}$ & $0.855-0.957(0.915)$ & $0.916-0.973(0.961)$ \\
\hline $\mathrm{IO}-\mathrm{CC}^{\mathrm{b},{ }^{*}}$ & $0.540-0.795(0.667)$ & $0.797-0.919(0.824)$ \\
\hline $\mathrm{EO}-\mathrm{CC}^{\mathrm{a},{ }^{*}}$ & $0.746(0.101)$ & $0.866(0.081)$ \\
\hline NP/R-RAIO-CC ${ }^{b}$ & $0.233-0.806(0.566)$ & $0.576-0.844(0.771)$ \\
\hline $\mathrm{P} / \mathrm{L}-\mathrm{RAIO}-\mathrm{CC}^{\mathrm{b}}$ & $0.341-0.844(0.630)$ & $0.601-0.949(0.842)$ \\
\hline NP/R-IOEO-CC ${ }^{b, *}$ & $0.443-0.745(0.631)$ & $0.729-0.920(0.778)$ \\
\hline $\mathrm{P} / \mathrm{L}-\mathrm{IOEO}-\mathrm{CC}{ }^{\mathrm{b},{ }^{*}}$ & $0.224-0.724(0.563)$ & $0.638-0.882(0.755)$ \\
\hline NP/R-RAEO-CC ${ }^{b}$ & $0.672-0.785(0.715)$ & $0.629-0.839(0.748)$ \\
\hline P/L-RAEO-CC ${ }^{b}$ & $0.626-0.832(0.742)$ & $0.738-0.870(0.826)$ \\
\hline \multicolumn{3}{|l|}{ TE } \\
\hline ES-SI ${ }^{b, *}$ & $-0.329-0.020(-0.178)$ & $-0.102-0.052(-0.057)$ \\
\hline LD-SI ${ }^{\text {a }}$ & $-0.013(-0.282)$ & $-0.046(-0.291)$ \\
\hline $\mathrm{ES}-\mathrm{CC}^{\mathrm{b},{ }^{*}}$ & $0.411-0.699(0.572)$ & $0.791-0.904(0.884)$ \\
\hline $\mathrm{LD}-\mathrm{CC}^{\mathrm{b}}$ & $0.656-0.833(0.750)$ & $0.580-0.800(0.751)$ \\
\hline NP/R-ESLD-CC ${ }^{\text {a }}$ & $0.729(0.121)$ & $0.763(0.109)$ \\
\hline $\mathrm{P} / \mathrm{L}_{-E S L D-C C}{ }^{\mathrm{b}}$ & $0.667-0.847(0.801)$ & $0.649-0.884(0.827)$ \\
\hline
\end{tabular}

SI: symmetry index; CC: cross-correlation; NP/R: non-paretic side of the patients/right side of the healthy controls; P/L: paretic side of the patients/left side of the controls $* \mathrm{p}<0.05$

a Normally distributed data are expressed as the mean (SD)

${ }^{\mathrm{b}}$ Mann-Whitney U test. Non-normally distributed data are presented as ranges of 25 th and 75th percentiles (median)

the prime movers for the movement tasks performed. These trunk muscles included the RA, EO, internal abdominal oblique (IO), ES, and LD according to the guidelines of electrode placement by Cram et $\mathrm{al}^{26)}$. A 6-camera motion analysis system (Qualisys Oqus, Qualisys Medical AB, Partille, Sweden) was used to record body kinematics during trunk position sense tests. Retroreflective markers were attached at anatomical landmarks according to the guidelines for the Visual3D kinematics model (C-Motion, Germantown, MD, USA).

The EMG signal was sampled at $1,500 \mathrm{~Hz}$, and the raw data were processed with band-pass filtering $(40-400 \mathrm{~Hz})$ and full-wave rectification. Computer algorithms written in MATLAB platform (V. 6.5, The MathWorks Inc., Natick, MA, USA) were used to calculate variables of interest. SI was defined by the following formulas: $[(\mathrm{P}-\mathrm{NP}) /(\mathrm{P}+\mathrm{NP})]$ for the stroke group and $[(\mathrm{L}-\mathrm{R}) /(\mathrm{L}+\mathrm{R})]$ for the control group, where $\mathrm{P}$ is the paretic side, NP is the non-paretic side, $\mathrm{L}$ is the left side, and $\mathrm{R}$ is the right side ${ }^{12)}$. Temporal synchronization was expressed by calculating the cross-correlation between the activity profiles of the corresponding muscles ${ }^{12}$. The TRE was calculated as the difference in thigh to trunk angle between the target position angle and reposition angle ${ }^{16)}$. The mean value from three trials in all tests was used for further analyses.

All statistical analyses were conducted by using SPSS for Windows, version 17 (SPSS Inc, Chicago, IL, USA). The statistical significance level for all tests was set at $\mathrm{p}<$
0.05 . The independent $t$ test and a nonparametric test (MannWhitney $U$ test) were used to investigate group differences in the variables with normal and non-normal distributions. To establish the association between neuromuscular control and trunk proprioception, Spearman correlations were used to test the relationships between EMG variables from trunk movement tests and TRE in the stroke and control groups. The number of subjects included in each group was limited, and the patient population recruited in this study had a high level of function. Therefore, these two groups were lumped together for further correlation analyses.

\section{RESULTS}

The SI values ranged from 0 (full symmetry) to 0.5 (full asymmetry). A positive value indicated a higher degree of activation on the paretic side in patients or the left side in healthy controls, and a negative value indicated a higher degree of activation on the non-paretic side in patients or the right side in healthy controls. The SI value of the IO muscle on the paretic side in the stroke group was lower than that on the non-paretic side in the control group during TF (Table 1, $\mathrm{t}=2.461, \mathrm{p}=0.020$ ), but there were no differences in the SI values of the RA $(Z=-0.394, p=0.694)$ and $E O(t=0.437$, $\mathrm{p}=0.665)$. For TE, the SI values of the ES was lower in the stroke group than in the control group $(Z=-2.012, p=0.044)$, but no significant difference was found in the LD muscle pair $(\mathrm{t}=-0.314, \mathrm{p}=0.756)$. 
Table 2. Trunk reposition error (TRE) differences between groups

\begin{tabular}{lcc}
\hline & Stroke & Control \\
\hline TRE-E & & \\
TRE-sagittal (degrees) & & \\
TRE-frontal (degrees) & $1.444-3.521(2.555)$ & $0.790-2.381(1.253)$ \\
TRE-F & $0.744-2.174(1.592)$ & $0.572-1.080(0.724)$ \\
TRE-sagittal (degrees) & $1.458-4.795(2.187)$ & $1.793-2.988(2.223)$ \\
TRE-frontal (degrees) & $0.440-1.399(0.926)$ & $0.325-1.464(0.574)$ \\
\hline * p $<0.05$ & & \\
All data were not normally distributed, so the data are presented as ranges of 25th and 75th \\
percentiles (median).
\end{tabular}

Table 3. Relationships between TRE and EMG data

\begin{tabular}{|c|c|c|c|c|c|c|c|c|c|c|c|c|}
\hline & \multicolumn{6}{|c|}{ TRE-F (degrees) } & \multicolumn{6}{|c|}{ TRE-E (degrees) } \\
\hline & \multicolumn{3}{|c|}{ Sagittal plane } & \multicolumn{3}{|c|}{ Frontal plane } & \multicolumn{3}{|c|}{ Sagittal plane } & \multicolumn{3}{|c|}{ Frontal plane } \\
\hline & All & $\mathrm{S}$ & $\mathrm{C}$ & All & $\mathrm{S}$ & $\mathrm{C}$ & All & $\mathrm{S}$ & $\mathrm{C}$ & All & $\mathrm{S}$ & $\mathrm{C}$ \\
\hline RA-SI & 0.192 & 0.179 & 0.207 & 0.207 & 0.325 & 0.079 & 0.312 & -0.007 & $0.521^{*}$ & -0.062 & -0.164 & -0.057 \\
\hline IO-SI & 0.185 & 0.336 & 0.011 & 0.352 & $0.625^{*}$ & 0.111 & 0.014 & -0.075 & -0.296 & 0.163 & 0.189 & -0.107 \\
\hline EO-SI & 0.274 & $0.589^{*}$ & -0.239 & -0.086 & 0.318 & $-0.614^{*}$ & -0.014 & -0.039 & 0.025 & -0.061 & -0.068 & -0.146 \\
\hline $\mathrm{RA}-\mathrm{CC}$ & -0.070 & 0.168 & -0.397 & -0.168 & 0.271 & $-0.521^{*}$ & $-0.461^{*}$ & -0.093 & -0.445 & $-0.367^{*}$ & -0.311 & -0.233 \\
\hline $\mathrm{IO}-\mathrm{CC}$ & -0.203 & -0.271 & -0.282 & 0.034 & 0.089 & 0.130 & -0.303 & -0.411 & 0.315 & -0.054 & 0.007 & 0.331 \\
\hline $\mathrm{EO}-\mathrm{CC}$ & 0.043 & 0.043 & 0.032 & -0.162 & -0.279 & 0.066 & -0.250 & -0.229 & 0.129 & -0.354 & $-0.543^{*}$ & 0.045 \\
\hline NP/R-RAIO-CC & -0.152 & -0.154 & -0.136 & -0.075 & -0.164 & 0.038 & -0.269 & -0.486 & 0.186 & -0.180 & -0.407 & 0.366 \\
\hline P/L-RAIO-CC & -0.156 & -0.232 & -0.143 & -0.069 & -0.396 & 0.281 & -0.135 & -0.346 & 0.450 & 0.022 & -0.139 & $0.627^{*}$ \\
\hline NP/R-IOEO-CC & 0.086 & 0.146 & 0.114 & -0.126 & -0.204 & -0.038 & $-0.380^{*}$ & -0.471 & 0.179 & -0.213 & -0.282 & 0.159 \\
\hline P/L-IOEO-CC & -0.089 & -0.175 & 0.082 & -0.209 & -0.429 & 0.116 & -0.205 & -0.279 & 0.425 & -0.131 & -0.107 & 0.320 \\
\hline NP/R-RAEO-CC & 0.358 & 0.475 & 0.332 & 0.113 & 0.329 & -0.020 & 0.083 & 0.096 & 0.239 & 0.008 & -0.139 & 0.220 \\
\hline P/L-RAEO-CC & 0.144 & 0.154 & 0.193 & 0.012 & 0.189 & 0.070 & -0.012 & 0.029 & 0.164 & -0.010 & -0.143 & 0.234 \\
\hline \multicolumn{13}{|l|}{ TE } \\
\hline ES-SI & 0.157 & -0.079 & 0.289 & 0.153 & 0.004 & 0.343 & 0.049 & -0.457 & 0.136 & 0.081 & 0.054 & -0.146 \\
\hline LD-SI & 0.136 & 0.000 & 0.457 & -0.202 & -0.279 & -0.004 & -0.274 & 0.004 & -0.471 & 0.100 & 0.207 & 0.075 \\
\hline ES-CC & 0.038 & 0.111 & 0.204 & -0.018 & 0.111 & 0.121 & $-0.397^{*}$ & 0.018 & -0.211 & -0.199 & -0.232 & 0.329 \\
\hline LD-CC & -0.102 & 0.075 & -0.325 & -0.143 & 0.032 & -0.318 & -0.154 & 0.061 & -0.318 & 0.106 & -0.018 & 0.154 \\
\hline NP/R-ESLD-CC & 0.118 & 0.408 & -0.207 & -0.141 & 0.325 & $-0.575^{*}$ & -0.155 & -0.071 & -0.121 & -0.333 & -0.391 & -0.332 \\
\hline P/L-ESLD-CC & 0.051 & 0.086 & 0.032 & 0.030 & 0.304 & -0.207 & -0.326 & -0.004 & -0.475 & 0.063 & 0.093 & 0.071 \\
\hline
\end{tabular}

S: stroke; C: control

$* \mathrm{p}<0.05$

Data are presented as Spearman correlation coefficients.

During TF, all cross-correlation values between homologous muscles were significantly lower in the stroke group than in the control group (Table 1; RA, $Z=-2.427$, $\mathrm{p}=0.015 ; \mathrm{IO}, \mathrm{Z}=-3.090, \mathrm{p}=0.002 ; \mathrm{EO}, \mathrm{t}=-3.596, \mathrm{p}=0.001$ ). Two synergistic ipsilateral trunk muscles, IO and EO from the non-paretic or right side $(Z=-2.717, p=0.007)$ and the paretic or the left side $(Z=-2.634, p=0.008)$, were also lower in the stroke group. During TE, only the cross-correlation of homologous ES was significantly different between groups $(\mathrm{Z}=-4.003, \mathrm{p}<0.001)$.

The TRE-E value measured from the sagittal plane was greater in the stoke group than in the control group (Table 2, $\mathrm{Z}=-2.302, \mathrm{p}=0.021$ ), but this was not the case for those measured from the frontal plane $(Z=-1.804, p=0.071)$. In TRE-F, the TRE values were not different between groups.

Correlation coefficients for the relationships between EMG variables and TRE are shown in Table 3. In all subjects, the EMG cross-correlation variables from TF or TE were negatively correlated with TRE-E in the sagittal plane. Higher the TRE-F was correlated with the SI values of the IO and EO in the stroke group, and the SI values of the RA in the control group during trunk flexion movement. The cross-correlation variables from TF and TE were negatively correlated with TRE-E or TRE-F in the stroke group or the control groups, but no significant correlation was found between TRE and the SI variables during trunk extension. 


\section{DISCUSSION}

The findings of the present study suggest that impairments in trunk control do exist in chronic stroke patients. In addition, lower values of temporal synchronization in trunk muscles and their counterparts on the opposite sides during voluntary TF and TE were related to higher TRE values in TRE-E in all subjects. As EMG reflects the status of neuromuscular control of the central as well as peripheral nervous systems, any abnormality in EMG indicates a deficit in motor control in stroke patients. In spite of the fact that TF and TE are bilaterally symmetric and that axial trunk muscles receive more bilateral hemispheric input ${ }^{9-11)}$, the stroke patients showed less symmetrical muscle activation and lower temporal synchronization in trunk muscles.

During TF, the degrees of cross-correlations between bilateral abdominal muscles were degraded in the stroke patients. Higher cross-correlation of corresponding bilateral muscles indicated higher temporal synchronization in muscle activation. Our results are consistent with those of a previous study ${ }^{12)}$. Moreover, the cross-correlation of the IO and EO pair on the paretic or non-paretic side was lower in the stroke patients, indicating persistent deficits in the efficiency of motor unit recruitment in chronic stroke patients. The results for the SI of the IO showed that the muscle activation level on the non-paretic side in the stroke group was higher than that on the paretic side, but no such difference existed in the control group. The results of the current study were not consistent with those of a study by Dickstein et al. ${ }^{12)}$, who reported that the activity of the RA on the paretic side was reduced when compared with that of the RA on the non-paretic side during trunk flexion. This study examined the muscle activities of the RA and EO, as did the previous study, and examined the IO to elucidate the roles of different stabilizers. Trunk muscles are classified as belonging either to the global system or local system $\left.{ }^{9}, 27\right)$. The muscles of the global system consist of muscles that play roles as prime movers and are capable of increasing intra-abdominal pressure. Muscles of the local system play roles to maintain the stability of the lumbar spine and usually have their origins and/or insertions attached to the spine. Although IO muscles provide trunk movements and compress abdominal viscera to increase intra-abdominal pressure, previous researchers suggested that IO fibers also contribute to enhancement of the stability of the spine via their attachment to the thoracolumbar fascia ${ }^{28,29)}$. Thus, the roles of the RA and EO are different from those of the lower fibers of the IO. In addition, the patients in this study were in the chronic stage and were younger than those in the study of Dickstein et $\mathrm{al}^{12)}$. Therefore, this might partially explain the inconsistency found between the studies. Further study is necessary to examine patients with stroke at different stages of recovery longitudinally in order to clarify trunk muscle function.

During TE, the cross-correlation and SI values of the ES in the stroke group were lower than those in the control group. However, no such differences were found in the LD muscles. The results of the current study were not consistent with those of Dickstein et al. ${ }^{12)}$, and this was most likely the consequence of differences in the trunk extension move- ments employed in the different studies. Movement in the previous study was initiated from trunk flexion with the forehead touching a table placed in front of the seated subject to the upright sitting posture ${ }^{12)}$, and it was shown that stroke patients had lower SI values for the LD muscle and crosscorrelation values for the LD and ES than control subjects. Compared with the task in this previous report, the ranges of the TE in the current study might have been larger. Movement with a larger range into positions of greater gravity influence demands more activation of the related muscle groups ${ }^{30)}$, especially those that function to stabilize proximal body parts. In TE, the contributions of the ES and LD muscles might also be different. The LD muscle is a prime mover for the shoulder (adduction, extension, and internal rotation) and participates in rotation, lateral flexion, and extension of the trunk ${ }^{26,27)}$, while the ES not only plays a role in extending the spine but also provides stability by increasing the tension of thoracolumbar fascia ${ }^{31)}$. It is likely that the TE employed in the current study, which started in a more flexed position, imposed a greater demand on the muscles tested, and it may constitute a task that better reflects the impairment of lumbar ES muscles in chronic stroke patients.

In the present study, trunk reposition ability was impaired in the stroke group compared with the control group as evidenced by a larger reposition error for TRE-E in stroke group in the sagittal plane. This result was similar to the findings reported by Ryerson et al. ${ }^{16)}$, who used an electromagnetic motion analysis system to investigate trunk position sense in poststroke patients. The movement range employed in Ryerson's study was from the upright position to a trunk forward flexion position, while in the current study, TRE was assessed from the upright position to trunk forward flexion and backward extension positions. Motor and sensory deficits are two of the major factors influencing performance in the trunk reposition test; therefore, the magnitude of TRE obtained in the current study represented integrated action of the sensory and motor components. TRE measurement in the current study was performed with an active reposition sense test, so the investigators selected only those patients who were capable of performing the TRE task. However, there were differences in task difficulties between forward and backward trunk reposition tests. Maintaining a backward position in which the center of mass (COM) moves backward toward and then outside of the border of the base of support is much more difficult than maintaining a moving forward position, as the COM falls between feet in the front and ischial tuberosities in the back. A previous study investigated older adults sitting on a force plate to determine the effect of reach in multiple directions on seated postural stability ${ }^{32)}$. The forward displacement of the center of pressure (COP) achieved was two times greater than the backward displacement. Therefore, subjects would lose their balance more easily in the backward direction than in the forward direction. Therefore, differences in trunk stability and base of support imposed during flexion and extension reposition tests might have accounted for the greater variability in TRE-E.

This study investigated the association between the trunk position sense and EMG variables in stroke and control groups. In the stroke group, less asymmetry in the IO and EO and lower temporal synchronization in the EO during 
TF were correlated with higher TRE-E or higher TRE-F, but there was no significant correlation between TRE and EMG variables during TE. In the control group, less asymmetry and lower temporal synchronization in the RA were correlated with higher TRE-E, and lower temporal synchronization in the right ES and LD muscles was correlated with higher TRE-F. Associations between TRE and the deficits of the IO and EO muscles were noticed in the stroke group, and this was consistent with the results of group comparisons during TF in this study. However, this study also assessed the association in all subjects due to the limited numbers of the subjects in both groups and the higher function of the patient population that was recruited. Higher cross-correlations in the bilateral RA and IO, EO on the non-paretic side observed during trunk flexion and bilateral ES during trunk extension were correlated with a smaller TRE in TRE-E. Our results indicated that TRE appears to be related to muscle temporal control (cross-correlation) but not the relative amount of bilateral muscle activation (SI). Both TRE-E and voluntary trunk extension movement extend the trunk backward in the sagittal plane with significant correlation between crosscorrelation of the back muscles and TRE-E. Additionally, the testing position of TRE-E was from the upright position to trunk backward extension. It was the same range of motion as TF, which was from a position with the trunk reclining backward at a thigh to trunk angle of $130^{\circ}$ to the upright position. Thus, an association was noticed between the cross-correlation of abdominal muscles during $\mathrm{TF}$ and TRE-E. The cross-correlation values of the RA, IO, EO, and ES during trunk flexion and extension were associated with TRE-E, and this suggests that future studies should add the TRE in the extension direction to the trunk position sense. Based on the results of the current study, trunk position sense did correlate with motor function.

One of the limitations of the present study was that the numbers of subjects in the chronic stroke group and agematched control group were relatively small. Future studies with larger samples of subjects are necessary. The stroke subjects recruited in the present study were patients with chronic stroke and higher functional levels (moderate to very good score for the Trunk Impairment Scale and high score for the Barthel Index), and therefore, this may limit generalization of the results of the present study to patients of different functional status.

The trunk muscle functions of patients with chronic stroke were impaired with respect to bilateral muscle activation and temporal synchronization during voluntary trunk movements. Patients also showed larger TRE values than healthy subjects, especially in the trunk extension direction. Higher TRE values were associated with deficits in the IO and EO muscles in stroke patients. TRE was also correlated with bilateral temporal synchronization of the RA, EO, and IO in trunk flexion and ES in trunk extension in all subjects. Future studies should pay more attention to symmetrical trunk movements as well as trunk position sense in the extension direction in chronic stroke patients.

\section{REFERENCES}

1) Tanaka S, Hachisuka $\mathrm{K}$, Ogata $\mathrm{H}$ : Muscle strength of trunk flexion-extension in post-stroke hemiplegic patients. Am J Phys Med Rehabil, 1998, 77: 288-290. [Medline] [CrossRef]

2) Fujita $T$, Sato A, Togashi $Y$, et al.: Contribution of abdominal muscle strength to various activities of daily living of stroke patients with mild paralysis. J Phys Ther Sci, 2015, 27: 815-818. [Medline] [CrossRef]

3) Hyngstrom AS, Kuhnen HR, Kirking KM, et al.: Functional implications of impaired control of submaximal hip flexion following stroke. Muscle Nerve, 2014, 49: 225-232. [Medline] [CrossRef]

4) Suzuki M, Fujisawa H, Machida Y, et al.: Relationship between the Berg balance scale and static balance test in hemiplegic patients with stroke. J Phys Ther Sci, 2013, 25: 1043-1049. [Medline] [CrossRef]

5) Dickstein R, Shefi S, Marcovitz E, et al.: Anticipatory postural adjustment in selected trunk muscles in post stroke hemiparetic patients. Arch Phys Med Rehabil, 2004, 85: 261-267. [Medline] [CrossRef]

6) Hsieh CL, Sheu CF, Hsueh IP, et al.: Trunk control as an early predictor of comprehensive activities of daily living function in stroke patients. Stroke, 2002, 33: 2626-2630. [Medline] [CrossRef]

7) Franchignoni FP, Tesio L, Ricupero C, et al.: Trunk control test as an early predictor of stroke rehabilitation outcome. Stroke, 1997, 28: 1382-1385. [Medline] [CrossRef]

8) Verheyden G, Vereeck L, Truijen S, et al.: Trunk performance after stroke and the relationship with balance, gait and functional ability. Clin Rehabil, 2006, 20: 451-458. [Medline] [CrossRef]

9) Palmer E, Ashby P: Corticospinal projections to upper limb motoneurones in humans. J Physiol, 1992, 448: 397-412. [Medline] [CrossRef]

10) Ferbert A, Caramia D, Priori A, et al.: Cortical projection to erector spinae muscles in man as assessed by focal transcranial magnetic stimulation. Electroencephalogr Clin Neurophysiol, 1992, 85: 382-387. [Medline] [CrossRef]

11) Carr LJ, Harrison LM, Stephens JA: Evidence for bilateral innervation of certain homologous motoneurone pools in man. J Physiol, 1994, 475: 217-227. [Medline] [CrossRef]

12) Dickstein R, Shefi S, Marcovitz E, et al.: Electromyographic activity of voluntarily activated trunk flexor and extensor muscles in post-stroke hemiparetic subjects. Clin Neurophysiol, 2004, 115: 790-796. [Medline] [CrossRef]

13) Dickstein R, Heffes Y, Laufer Y, et al.: Activation of selected trunk muscles during symmetric functional activities in poststroke hemiparetic and hemiplegic patients. J Neurol Neurosurg Psychiatry, 1999, 66: 218-221. [Medline] [CrossRef]

14) Dickstein R, Sheffi $S$, Ben Haim Z, et al.: Activation of flexor and extensor trunk muscles in hemiparesis. Am J Phys Med Rehabil, 2000, 79: 228-234. [Medline] [CrossRef]

15) Hodges P, Cresswell A, Thorstensson A: Preparatory trunk motion accompanies rapid upper limb movement. Exp Brain Res, 1999, 124: 69-79. [Medline] [CrossRef]

16) Ryerson S, Byl NN, Brown DA, et al.: Altered trunk position sense and its relation to balance functions in people post-stroke. J Neurol Phys Ther, 2008, 32: 14-20. [Medline] [CrossRef]

17) Goldberg A, Hernandez ME, Alexander NB: Trunk repositioning errors are increased in balance-impaired older adults. J Gerontol A Biol Sci Med Sci, 2005, 60: 1310-1314. [Medline] [CrossRef]

18) Goldberg A, Russell JW, Alexander NB: Standing balance and trunk position sense in impaired glucose tolerance (IGT)-related peripheral neuropathy. J Neurol Sci, 2008, 270: 165-171. [Medline] [CrossRef]

19) Noh KH, Oh JS, Yoo WG: Comparison of lumbar repositioning error according to different lumbar angles in a flexion pattern (FP) subgroup of patients with non-specific chronic low back pain. J Phys Ther Sci, 2015, 27: 293-294. [Medline] [CrossRef]

20) Son SM, Kwon YH, Lee NK, et al.: Deficits of movement accuracy and proprioceptive sense in the Ipsi-Iesional upper limb of patients with hemiparetic stroke. J Phys Ther Sci, 2013, 25: 567-569. [Medline]

21) Lin PY, Yang YR, Cheng SJ, et al.: The relation between ankle impairments and gait velocity and symmetry in people with stroke. Arch Phys Med Rehabil, 2006, 87: 562-568. [Medline] [CrossRef]

22) Lin SI: Motor function and joint position sense in relation to gait performance in chronic stroke patients. Arch Phys Med Rehabil, 2005, 86: 197203. [Medline] [CrossRef]

23) Soyuer F, Oztürk A: The effect of spasticity, sense and walking aids in falls of people after chronic stroke. Disabil Rehabil, 2007, 29: 679-687. [Medline] [CrossRef] 
24) Verheyden G, Nieuwboer A, Mertin J, et al.: The Trunk Impairment Scale: a new tool to measure motor impairment of the trunk after stroke. Clin Rehabil, 2004, 18: 326-334. [Medline] [CrossRef]

25) Kauhanen ML, Korpelainen JT, Hiltunen P, et al.: Domains and determinants of quality of life after stroke caused by brain infarction. Arch Phys Med Rehabil, 2000, 81: 1541-1546. [Medline] [CrossRef]

26) Cram JR, Kasman GS, Holtz J: Electrode Placements. In: Introduction to surface electromyography. Gaithersburg: Aspen Publishers, 1998.

27) Borghuis J, Hof AL, Lemmink KA: The importance of sensory-motor control in providing core stability: implications for measurement and training. Sports Med, 2008, 38: 893-916. [Medline] [CrossRef]

28) Tesh KM, Dunn JS, Evans JH: The abdominal muscles and vertebral stability. Spine, 1987, 12: 501-508. [Medline] [CrossRef]
29) Hodges PW, Richardson CA: Contraction of the abdominal muscles associated with movement of the lower limb. Phys Ther, 1997, 77: 132-142, discussion 142-144. [Medline]

30) Roy AL, Keller TS, Colloca CJ: Posture-dependent trunk extensor EMG activity during maximum isometrics exertions in normal male and female subjects. J Electromyogr Kinesiol, 2003, 13: 469-476. [Medline] [CrossRef]

31) Hukins DW, Aspden RM, Hickey DS: Thorecolumlbar fascia can increase the efficiency of the erector spinae muscles. Clin Biomech (Bristol, Avon), 1990, 5: 30-34. [Medline] [CrossRef]

32) Kerr HM, Eng JJ: Multidirectional measures of seated postural stability. Clin Biomech (Bristol, Avon), 2002, 17: 555-557. [Medline] [CrossRef] 